DOI: https://doi.org/10.24127/ajpm.v10i1.3245

\title{
IMPLEMENTASI MEANS-ENDS ANALYSIS DENGAN LIGHTENING THE LEARNING CLIMATE TERHADAP KEMAMPUAN PEMECAHAN MASALAH MATEMATIS
}

\author{
Nadia Safitri $^{*}$, Mujib ${ }^{2}$, Sri Purwanti Nasution ${ }^{3}$ \\ ${ }^{1 * 2,3}$ Pendidikan Matematika, Universitas Islam Negeri Raden Intan Lampung \\ *Corresponding author. \\ E-mail: $\quad \frac{\text { nadiasafitri054@gmail..com }}{\text { mujibzahra@gmail.com }^{2)}}$ \\ sripurwanti@yahoo.co.id ${ }^{3)}$
}

Received 15 November 2020; Received in revised form 09 March 2021; Accepted 03 April 2021

\begin{abstract}
Abstrak
Penelitian ini dilatarbelakangi oleh pengamatan di SMP Karya Bhakti Panaragan menunjukkan kemampuan pemecahan masalah matematis peserta didik masih terbilang rendah. Tujuan penelitian ini adalah untuk mengetahui apakah ada pengaruh dari model pembelajaran Means-Ends Analysis (MEA) dengan strategi pembelajaran Lightening The Learning Climate terhadap kemampuan pemecahan masalah matematis peserta didik kelas VII SMP Karya Bhakti Panaragan. Metode yang digunakan dalam penelitian ini menggunakan metode kuantitatif. Pengambilan subjek pada penelitian ini adalah menggunakan teknik acak kelas. Subjek yang digunakan dalam penelitian ini adalah 3 kelas VII berjumlah 30 peserta didik. Teknik pengumpulan data yang digunakan dalam penelitian ini adalah Tes dan Dokumentasi. Tes dalam penelitian ini untuk mengukur kemampuan pemecahan masalah matematis peserta didik menggunakan tes berbentuk uraian sebanyak 8 soal. Teknik analisis data yang digunakan adalah validitas, taraf kesukaran, daya pembeda, dan reliabilitas. Teknik Uji prasyarat adalah normalitas, homogenitas. Uji hipotesis menggunakan uji anava satu arah dan uji scheffe. Hasil penelitian ini adalah uji anava satu jalan menghasilkan nilai sig. $<0,05$ yang artinya $\mathrm{H}_{0}$ ditolak menunjukkan bahwa terdapat pengaruh penggunaan model pembelajaran Means-Ends Analysis (MEA) dengan strategi Lightening The Learning Climate terhadap kemampuan pemecahan masalah matematis peserta didik.
\end{abstract}

Kata kunci: Kemampuan pemecahan masalah matematis; lightening the learning climate; means-ends analysis (MEA)

\begin{abstract}
This research was motivated by observations at SMP Karya Bhakti Panaragan showing that students' mathematical problem solving abilities were still relatively low. The purpose of this research was to determine whether there is an effect of the Means-Ends Analysis (MEA) learning model with the Lightening the Learning Climate learning strategy on the mathematical problem solving abilities of seventh grade students of SMP Karya Bhakti Panaragan. The method used in this research is quantitative methods. Taking the subject in this study was using a randomized class technique. The subjects used in this study were 3 class VII totaled 30 students. Data collection techniques used in this study were tests and documentation. The test in this study was to measure students' mathematical problem solving abilities using a test in the form of a description of 8 questions. The data analysis techniques used were validity, level of difficulty, distinguishing power, and reliability. The prerequisite test techniques are normality, homogeneity. Hypothesis testing using one-way ANOVA test and Scheffe test. The results of this reseach indicate that One-way ANOVA test produces sig. $<0.05$, which means that $\mathrm{HO}$ is rejected there is an effect of the use of the Means-Ends Analysis (MEA) learning model with the Lightening the Learning Climate strategy on students' mathematical problem solving abilities.
\end{abstract}

Keywords: Lightening the learning climate; mathematical problem solving ability; means-ends analysis (MEA)

This is an open access article under the Creative Commons Attribution 4.0 International License 
DOI: https://doi.org/10.24127/ajpm.v10i1.3245

\section{PENDAHULUAN}

Pendidikan yaitu suatu usaha untuk menyesuaikan diri peserta didik dengan sebaik mungkin terhadap lingkungannya (Rachmawati et al., 2020). Matematika yang termasuk dalam sistem pendidikan nasional yaitu agar peserta didik memiliki kemampuan yang dapat diaplikasikan secara nyata di lingkungannya(Mulasari et al., 2020). Tujuan belajar matematika untuk membentuk pola pikir secara logis, kritis, sistematis dan konsisten(Amorie, 2015).

Means Ends Analysis (MEA) merupakan pengembangan suatu jenis pemecahan masalah dengan berdasarkan suatu strategi yang membantu peserta didik dalam menemukan cara penyelesaian masalah sebagai petunjuk dalam menetapkan cara yang paling efektif dan efisien (Sahrudin, 2016). Berpikir secara sistematis, kritis, logis, serta memiliki sikap pantang menyerah untuk menemukan solusi dari masalah yang dihadapi(Nengsih et al., 2019).

Adapun beberapa langkah strategi pembelajaran lightening the learning climate (LTLC) yang dapat diterapkan dalam proses pembelajaran, yaitu: a. Jelaskanlah kepada peserta didik bahwa anda akan memulai pelajaran/perkuliahan b.Bagi peserta didik ke dalam kelompok-kelompok kecil. c. Mintahlah kelompok-kelompok tadi untuk mempresentasikan kreasi mereka. d. Tanyatakan; Apa yang mereka pelajari tentang materi kita dari latihan ini ?"e. Guru memberi penjelasan atau melanjutkan pelajaran dengan materi lain (Untung, 2017).

Bell (1978: 119) menyatakan bahwa terdapat lima strategis yang berkaitan dengan pemecahan masalah dunia nyata yaitu: menyajikan masalah dalam bentuk jelas, menyatakan masalah, memperkirakan proses pemecahan masalah, menguji hipotesis untuk memperoles solusi, jika solusi telah ditemukan maka di periksa kembali apakah solusi tersebut benar namun jika diperoleh lebih dari satu solusi maka memilih solusi yang paling baik (Sumartini, 2016). Meningkatkan kemampuan pemecahan masalah peserta didik tentunya tidak dapat terlepas dari cara untuk meningkatkan keterampilan proses pembelajaran di sekolah(Natsir et al., 2019). Salah satu cara dengan mengganti pola pembelajaran yaitu pembelajaran yang awalnya berfokus dengan guru beralih berfokus dengan peserta didik. Pergantian ini bertujuan agar dapat menyempurnakan nilai pendidikan baik dari proses pembelajaran maupun dari hasil pembelajaran. Hasil pra survei di SMP Karya Bhakti Panaragan menunjukkan kemampuan pemecahan masalah matematis peserta didik masih terbilang rendah. Dari 86 peserta didik kelas VIII A, VIII B, VIII C, dan VIII D terdapat 2 peserta didik atau $2,3 \%$ yang mendapat nilai $\geq 68$ dan peserta didik yang mendapat nilai $<68$ sebanyak 84 orang atau $97,7 \%$.

Terdapat beberapa penelitian relevan yang sudah dilakukan yaitu peningkatan kemampuan pemecahan masalah dan komunikasi matematis peserta didik SMP melalui model pembelajaran means-ends analysis (MEA)(Juanda et al., 2014). Pengaruh penerapan model pembelajaran meansends analysis (MEA) terhadap hasil belajar fisika(Hartini \& Lianti, 2015). Implementasi model pembelajaran means-ends analysis (MEA) untuk meningkatkan kemampuan pemecahan masalah matematika mahapeserta didik(Sahrudin, 2016). Pengaruh model pembelajaran means-ends analysis (MEA) dengan setting belajar kelompok 
berbantuan LKS terhadap hasil belajar matematika peserta didik kelas IV SD Desa Bebetin(Harto et al., 2014). Kemampuan pemecahan masalah matematis peserta didik yang menggunakan model pembelajaran Means-Ends Analysis lebih baik dibandingkan peserta didik yang pembelajarannya menggunakan model pembelajaran langsung. Kemampuan pemecahan masalah akan lebih mudah jika penyusunan solusi lebih terstruktur, seperti mencatat sebuah permasalah dari sebab dan akibat, merumuskan hipotesis, memilih prosedur dalam menyelesaikan permasalahan, lalu kesimpulan dan ini terdapat dalam langkah strategi pembelajaran lightening the learning climate .

Sehingga dari penelitian yang sebelumnya belum ada yang meneliti pengaruh model pembelajaran meansends analysis (MEA) dengan strategi lightening the learning climate terhadap kemampuan pemecahan masalah matematis, maka terdapat keterbaharuan (Novelty) yaitu menggunakan model pembelajaran means-ends analysis (MEA) dengan strategi pembelajaran lightening the learning climate dan melihat bagaimana pengaruh model pembelajaran ini terhadap kemampuan pemecahan masalah matematis peserta didik dengan tujuan agar pemahaman matematika peserta didik baik terkhusus pada kemampuan pemecahan masalah matematis.

Berdasarkan uraian yang telah dijelaskan maka tujuan penelitian ini adalah untuk mengetahui apakah ada pengaruh dari model pembelajaran Means-Ends Analysis (MEA) dengan strategi pembelajaran Lightening The Learning Climate terhadap kemampuan pemecahan masalah matematis peserta didik kelas VII SMP Karya Bhakti Panaragan.

\section{METODE PENELITIAN}

Jenis penelitian yang dilakukan dalam penelitian ini adalah pendekatan kuantitatif. Jenis eksperimen yang dipakai merupakan Quasy Experiment, yaitu desain yang mempunyai kelompok kontrol, akan tetapi tidak bisa berfungsi sepenuhnya untuk memeriksa variabelvariabel luar yang berpengaruh terhadap penerapan eksperimen. Pengambilan subjek pada penelitian ini adalah menggunakan teknik acak kelas (Sugiyono, 2013). Subjek yang digunakan dalam penelitian ini adalah 3 kelas VII yang berjumlah 30 peserta didik. Teknik pengumpulan data yang digunakan dalam penelitian ini adalah Tes dan Dokumentasi. Tes dalam penelitian ini untuk mengukur kemampuan pemecahan masalah matematis peserta didik menggunakan tes berbentuk uraian sebanyak 8 soal. Instrumen yang digunakan untuk mengumpulkan data yaitu tes pemecahan masalah matematis berupa pertanyaan tentang materi pembelajaran matematika.

Rancangan penelitian ini yang dilakukan yaitu memilih sekolah, kemudian memilih tiga kelas yang akan dijadikan sampel. Kelas pertama (kelas eksperimen 1) dengan model pembelajaran means-ends analysis (MEA) dengan strategi lightening the learning climate, kelas kedua (kelas eksperimen 2) dengan model pembelajaran means-ends analysis (MEA), sedangkan kelas ketiga (kelas kontrol) dengan model pembelajaran konvensional.

Tes dilakukan agar dapat mengetahui kemampuan pemecahan masalah matematis. Tes ini juga digunakan untuk memperoleh data dari variabel bebas yaitu pembelajaran Means-Ends Analysis (MEA) dengan strategi Lightening The Learning 
Climate peserta didik berdasarkan indikatornya. Dokumentasi yang digunakan dalam penelitian ini adalah dokumentasi nilai peserta didik, berupa foto saat proses pembelajaran dan beberapa lembar jawaban peserta didik tentang pemecahan masalah matematis terhadap pembelajaran Means-Ends Analysis (MEA) dengan strategi Lightening The Learning Climate peserta didik.

Teknik analisis data yang digunakan adalah validitas, taraf kesukaran, daya pembeda, dan reliabilitas. Teknik Uji prasyarat adalah normalitas, homogenitas. Uji hipotesis menggunakan uji anava satu arah dan uji scheffe.

\section{HASIL DAN PEMBAHASAN}

Penelitian ini menggunakan tes uraian (essay) untuk memperoleh data kemampuan pemecahan masalah matematis peserta didik. Sebelum instrumen tes kemampuan pemecahan masalah matematis ini digunakan dalam penelitian terlebih dahulu dilakukan uji coba yang dilakukan di luar kelas eksperimen maupun kelas kontrol.Uji coba instrumen dilakukan di kelas VIII SMP Karya Bhakti Panaragan yang berjumlah 30 peserta didik dengan memberikan 8 butir soal kemampuan pemecahan masalah matematis. Kelebihan dalam penelitian ini adalah peserta didik dapat berpikir lebih kreatif, lebih teliti terhadap suatu masalah, dan dapat menambah wawasan pengalaman peserta didik yang lebih luas agar dapat menemukan sesuatu dalam menjawab sebuah pertanyaan dengan cara diskusi kelompok. Kekurangannya adalah peserta didik masih dibantu oleh guru dalam memecahkanmasalah yang diberikan sehingga memerlukan waktu yang cukup lama dalam proses pembelajaran.

Berdasarkan hasil perhitungan uji validitas, uji reliabilitas, uji tingkat kesukaran, dan uji daya beda maka dapat dibuat kesimpulan seperti pada Tabel 1.

Tabel 1. Kesimpulan hasil uji coba tes kemampuan pemecahan masalah matematis.

\begin{tabular}{cccccc}
\hline No & Validitas & $\begin{array}{c}\text { Tingkat } \\
\text { Kesukaran }\end{array}$ & $\begin{array}{c}\text { Daya } \\
\text { Pembeda }\end{array}$ & Reliabilitas & Kesimpulan \\
\hline 1 & Valid & Sedang & Cukup & & Digunakan \\
2 & Valid & Sedang & Baik & & Digunakan \\
3 & Invalid & Sukar & Jelek & & Tidak Digunakan \\
4 & Invalid & Sedang & Jelek & Reliabel & Tidak Digunakan \\
5 & Valid & Sukar & Cukup & & Digunakan \\
6 & Valid & Sedang & Baik & & Digunakan \\
7 & Valid & Sedang & Baik Sekali & & Digunakan \\
8 & Valid & Sedang & Cukup & & Digunakan \\
\hline
\end{tabular}

Berdasarkan hasil uji coba, maka dapat disimpulkan dari Tabel 1 dimana ada 6 soal yang yang digunakan dan ada 2 soal yang tidak gunakan. Soal yang digunakan artinya soal memenuhi aspek validitas hingga reliabilitas dan layak karena petunjuk pengisian dan butir item pertanyaan sudah dipahami oleh responden dan butir-butir pertanyaan jelas (Hardani et al., 2020), namun sebaliknya dengan 2 soal yang tidak digunakan. Hasil rekapitulasi analisis butir soal tes kemampuan pemecahan masalah matematis juga menjelaskan bahwa ke 6 soal tersebut memuat semua indikator dari 
kemampuan pemecahan masalah matematis dan ke 6 soal tersebut dianggap mampu mengukur kemampuan pemecahan masalah matematis peserta didik.

Perhitungan reliabilitas digunakan untuk mengukur sejauh mana hasil agar tetap konsisten, menggunakan rumus Alpha Cronbach untuk menghitung uji reliabilitas diperoleh seluruh soal reliabel, sebab 0,393 $\geq 0,361$. maka disimpulkan bahwa instrumen soal konsisten atau reliabel dan instrumen soal dapat digunakan. Hasil analisis deskripsi yang telah dilakukan menyimpulkan bahwa dari 8 soal yang digunakan sebanyak 6 soal yang terdiri dari soal sukar dan sedang, memiliki daya pembeda yaitu cukup, baik, dan baik sekali. Nilai kemampuan pemecahan masalah matematis peserta didik kelas eksperimen 1 mendapatkan nilai tertinggi 100 , kelas eksperimen 2 mendapatkan nilai tertinggi 100 dan kelas kontrol mendapatkan nilai tertinggi 86. Sedangkan nilai terendah pada kelas eksperimen 1 yaitu 55, kelas eksperimen 2 mendapatkan nilai terendah 43 dan kelas kontrol mendapat nilai terendah 31 . Nilai rata-rata (mean) pada kelas eksperimen 1 adalah 78,467 lebih besar dari nilai rata-rata kelas eksperimen 2 yaitu 72,233 dan kelas kontrol mendapatkan nilai rata-rata terendah yaitu 59,200 terdapat pada Tabel 2. Berdasarkan hasil analisis deskripsi, dapat disimpulkan bahwa rerata kemampuan siswa pada ketiga kelas uji coba memiliki perbedaan yang signifikan dan kedua kelas eksperimen memiliki kemampuan awal pemecahan masalah yang lebih baik daripada kelas kontrol.

Tabel 2. Deskripsi data nilai pemecahan masalah matematis

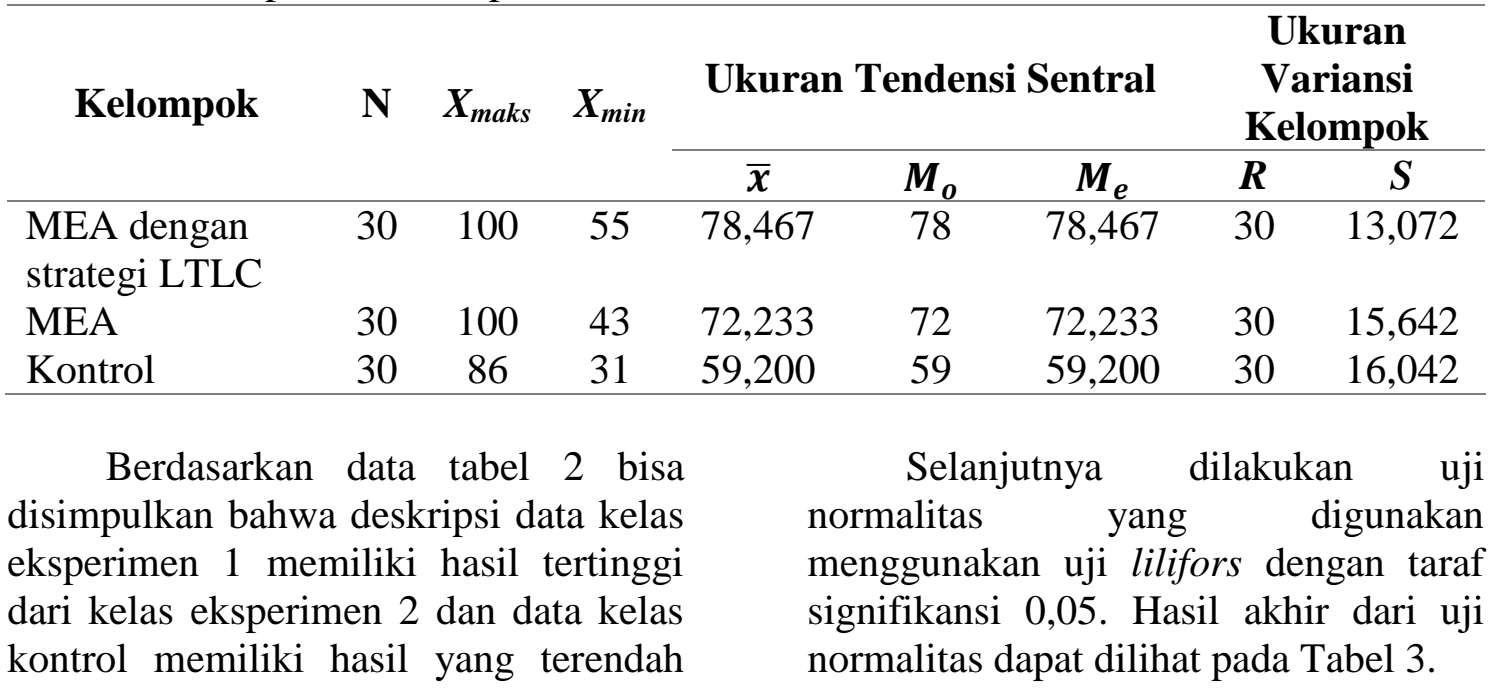
dari kelas eksperimen 1 dan eksperimen 2.

Tabel 3. Rangkuman Hasil Uji Normalitas Data Kemampuan Pemecahan Masalah Matematis

\begin{tabular}{clccc}
\hline No & \multicolumn{1}{c}{ Kelas } & L $_{\text {hitung }}$ & $\mathbf{L}_{\text {tabel }}$ & Keputusan Uji \\
\hline 1 & Eksperimen 1 $\left(\mathrm{A}_{1}\right)$ & 0,095 & 0,159 & $\mathrm{H}_{0}$ diterima \\
2 & Eksperimen 2 $\left(\mathrm{A}_{2}\right)$ & 0,089 & 0,159 & $\mathrm{H}_{0}$ diterima \\
3 & Kontrol $\left(\mathrm{A}_{3}\right)$ & 0,106 & 0,159 & $\mathrm{H}_{0}$ diterima \\
\hline
\end{tabular}


Berdasarkan Tabel 3, hasil data uji normalitas yang didapatkan yaitu nilai $\mathrm{L}_{\text {hitung }} \leq \mathrm{L}_{\text {tabel }}$ maka pada Eksperimen 1 didapatkan 0,095 $\leq 0,159$ , Eksperimen 2 didapatkan $0,089 \leq$ 0,159 , dan kontrol $0,106 \leq 0,159$ disimpulkan bahwa $\mathrm{H}_{0}$ diterima data pada setiap kelas berasal dari populasi yang berdistribusi normal.
Selanjutnya adalah perhitungan uji homogenitas. Uji homogenitas ini menggunakan uji Bartlett dimana uji homogenitas dilakukan untuk tes pada taraf signifikansi $(\alpha)=0,05$. Tes tersebut dapat dikatakan homogen jika $x^{2}$ hitung $<x^{2}$ tabel. Uji tersebut telah dicantumkan pada Tabel 4.

Tabel 4. Hasil uji homogenitas

\begin{tabular}{ccccc}
\hline No & Kelompok & $\chi^{2}$ tabel & $\chi^{2}$ hitung & Keputusan Uji \\
\hline 1 & $\mathrm{~A}_{1}$ & & & \\
2 & $\mathrm{~A}_{2}$ & 5,591 & 1,382 & $\mathrm{H}_{0}$ diterima \\
3 & $\mathrm{~A}_{3}$ & & & \\
\hline
\end{tabular}

Berdasarkan Tabel 4 yaitu hasil uji homogenitas, dapat disimpulkan dari kelompok tidak melebihi $\chi^{2}$ hitung $<\chi^{2}$ tabel. Perhitungan dari antar kelas eksperimen dan kelas kontrol maka diperoleh $\chi^{2}$ hitung $=1,382$ dengan $\chi^{2}$ tabel $=5,591$ maka $\mathrm{H}_{0}$ diterima. Jadi bisa disimpulkan bahwa sampel berasal dari populasi yang homogen.
Uji hipotesis dianalisis menggunakan uji anava satu jalan dengan tujuan dapat mengetahui apakah ada perbedaan terhadap kelas eksperimen dengan kelas kontrol memiliki kemampuan pemecahan masalah matematis yang sama. Hasil uji anava satu arah dengan menggunakan SPSS pada data disajikan pada Tabel 5.

Tabel 5. Hasil uji anava satu jalan

\begin{tabular}{lrrrrc}
\hline & Sum of Squares & df & Mean Square & F & \multicolumn{1}{c}{ Sig. } \\
\hline Between Groups & 5799.267 & 2 & 2899.633 & 12.928 & .000 \\
Within Groups & 19513.633 & 87 & 224.295 & & \\
Total & 25312.900 & 89 & & & \\
\hline
\end{tabular}

Berdasarkan Tabel 5 didapat bahawa sig, $<\alpha$, karena sig $0,000<$ 0,05 dapat menyimpulkan bahwa $\mathrm{H}_{0}$ ditolak sehingga ada minimal 1 pasang model memberikan rataan hasil yang berbeda. Setelah dilakukan komparansi ganda menggunakan metode scheffe, dengan bantuan SPSS diperoleh data multiple compararisons Tabel 6.

Tabel 6 Hasil uji komparansi ganda

\begin{tabular}{|c|c|c|c|c|c|c|}
\hline \multirow{2}{*}{ (I) $K E L A S$} & \multirow{2}{*}{ (J) KELAS } & \multirow{2}{*}{$\begin{array}{c}\text { Mean } \\
\text { Difference }(I-J)\end{array}$} & \multirow{2}{*}{$\begin{array}{c}\text { Std. } \\
\text { Error }\end{array}$} & \multirow{2}{*}{ Sig. } & \multicolumn{2}{|c|}{ 95\% Confidence Interval } \\
\hline & & & & & Lower Bound & Upper Bound \\
\hline Ekspe & Eksperimen 2 & 6.233 & 3.867 & .278 & -3.40 & 15.86 \\
\hline 1 & Kontrol & $19.267^{*}$ & 3.867 & .000 & 9.64 & 28.90 \\
\hline Eksperimen & Eksperimen 1 & -6.233 & 3.867 & .278 & -15.86 & 3.40 \\
\hline 2 & Kontrol & $13.033^{*}$ & 3.867 & .005 & 3.40 & 22.66 \\
\hline & Ekspe & $-19.267^{*}$ & 3.867 & .000 & -28.90 & -9.64 \\
\hline Kontrol & Eksperimen 2 & $-13.033^{*}$ & 3.867 & .005 & -22.66 & -3.40 \\
\hline
\end{tabular}


Berdasarkan hasil analisis uji hipotesis pada Tabel 5 dapat diketahui manakah model pembelajaran yang memberikan peningkatan paling berbeda terhadap kemampuan pemecahan masalah matematis peserta didik, melalui uji komparansi ganda (scheffe) menggunakan SPSS dengan analisis hasil sebagai berikut:

1. Analisis hasil terhadap hipotesis pertama $\left(\mu_{1}\right.$ vs $\left.\mu_{2}\right)$

Perhitungan uji anava satu jalan menghasilkan nilai sig. $>0,05$ yaitu $0,278>0,05$ yang berarti $\mathrm{H}_{0}$ diterima, sehingga tidak ada perbedaan hasil signifikan antara peserta didik dengan model pembelajaran Means-Ends Analysis (MEA) menggunakan strategi Lightening The Learning Climate dengan model pembelajaran MeansEnds Analysis (MEA) terhadap kemampuan pemecahan masalah matematis. Berdasarkan teori seharusnya model pembelajaran MeansEnds Analysis (MEA) menggunakan strategi Lightening The Learning Climate sama baiknya dengan model pembelajaran Means-Ends Analysis (MEA) terhadap kemampuan pemecahan masalah matematis peserta didik.

2. Analisis hasil terhadap hipotesis kedua ( $\mu_{1}$ vs $\left.\mu_{3}\right)$

Perhitungan uji anava satu jalan menghasilkan nilai sig. $<0,05$ yaitu $0,278>0,05 y a n g$ artinya $\mathrm{H}_{0}$ ditolak, sehingga ada perbedaan hasil signifikan antara peserta didik dengan model pembelajaran Means-Ends Analysis (MEA) menggunakan strategi Lightening The Learning Climate dengan model pembelajaran konvensional terhadap kemampuan pemecahan masalah matematis.

Pembelajaran Means-Ends Analysis (MEA) menggunakan strategi
Lightening The Learning Climate maupun pembelajaran konvensional berjalan dengan sangat baik, hanya saja peserta didik pada model pembelajaran konvensional kurang antusias dan terlihat pasif. Sehingga dari nilai ratarata yang didapat dapat disimpulkan bahwa model pembelajaran MeansEnds Analysis (MEA) menggunakan strategi Lightening The Learning Climate lebih baik dari model pembelajaran konvensional.

3. Analisis hasil terhadap hipotesis ketiga $\left(\mu_{2}\right.$ vs $\left.\mu_{3}\right)$

Perhitungan uji anava satu jalan mengasilkan nilai sig. $<0,05$ yaitu $0,000<0,05$ yang artinya $\mathrm{H}_{0}$ ditolak, sehingga ada perbedaan hasil signifikan antara peserta didik dengan model pembelajaran Means-Ends Analysis (MEA) dengan model pembelajaran konvensional terhadap kemampuan pemecahan masalah matematis.

Pembelajaran

Means-Ends Analysis (MEA) maupun pembelajaran konvensional berjalan dengan sangat baik, hanya saja peserta didik pada model pembelajaran konvensional kurang aktif saat pembelajaran berlangsung, akibatnya semangat peserta didik untuk memahami materi yang disampaikan berkurang. Sehingga disimpullkan bahwa nilai rata-rata yang diperoleh model pembelajaran MeansEnds Analysis (MEA) lebih baik dari model pembelajaran konvensional dan terdapat pengaruh penggunaan model pembelajaran Means-Ends Analysis (MEA) dengan strategi Lightening The Learning Climate terhadap kemampuan pemecahan masalah matematis peserta didik.

Beberapa hal yang ditemukan dalam penelitian, bahwa proses pembelajaran Means-Ends Analysis (MEA) menggunakan strategi 


\section{Lightening The Learning Climate} maupun pembelajaran Means-Ends Analysis (MEA) berjalan sangat baik dan antusias hanya saja peserta didik yang aktif dan menjawab yaitu peserta didik yang memiliki kemampuan awal tinggi saja. Selain itu, model pembelajaran Means-Ends Analysis (MEA) menggunakan strategi Lightening The Learning Climate lebih baik dari model pembelajaran konvensional.

Proses pembelajaran Means-Ends Analysis (MEA) menggunakan strategi Lightening The Learning Climate berjalan dengan hasil yang baik seperti apa yang dipaparkan di atas, sehingga penelitian ini berdampak terhadap, 1) model pembelajaran Means-Ends Analysis (MEA) menggunakan strategi Lightening The Learning Climate mampu merangsang peserta didik menjadi lebih aktif, 2) peserta didik dapat merespons setiap permasalahan yang diberikan dengan cara mereka sendiri, 3) mengemukakan idenya dalam proses pembelajaran sehingga peserta didik dapat menyelesaikan soalsoal yang berkaitan dengan pemecahan masalah sehingga kemampuan pemecahan masalah matematis peserta didik jauh lebih baik dari yang diharapkan peneliti, 4) Peningkatan kemampuan pemecahan masalah matematis siswa yang memperoleh matematika dengan model pembelajaran Means Ends analiysis lebih baik daripada siswa yang memperoleh pembelajaran matematika biasa, 5) Tidak terdapat perbedaan kemampuan pemecahan masalah matematis berdasarkan kemampuan awal matematika, dan 6) Secara umum sikap siswa terhadap pelaksanaan pembelajaran dengan model pembelajaran MEA adalah positif.
Adapun kelebihan dan kekurangan dalam penelitian ini, dimana kelebihannya yaitu peserta didik dapat berpikir lebih kreatif dan lebih teliti terhadap suatu masalah dan dapat menambah pengalaman peserta didik yang lebih luas agar dapat menemukan sesuatu yang mendalam utnuk menjawab prtanyaan dengan cara diskusi kelompok. Kekurangannya yaitu peserta didik masih dibantu oleh guru dalam memecahkan masalah yang diberikan sehingga memerlukan waktu yang cukup lama dalam proses pembelajaran.

Penelitian ini sejalan dengan penelitian (Nurhadi, 2017; Harto, Agung, \& Wibawa, 2014; Juanda, Johar, \& Ikhsan, 2014; Sari \& Masri, 2020; Asih, 2019) mengembangkan kemampuan pemecahan masalah menggunakan model pembelajaran Means-Ends Analysis (MEA) mencapai yang diharapkan, maka penelitian ini dibaharui model pembelajaran MeansEnds Analysis (MEA) dengan strategi Lightening The Learning Climate sehingga kemampuan pemecahan masalah matematis peserta didik menjadi lebih baik.

\section{KESIMPULAN DAN SARAN}

Berdasarkan hasil dan analisis data pengujian hipotesis yang telah dilakukan dapat disimpulkan bahwa terdapat pengaruh penggunaan model pembelajaran Means-Ends Analysis (MEA) dengan strategi Lightening The Learning Climate terhadap kemampuan pemecahan masalah matematis peserta didik.

Berdasarkan penelitian yang telah dilakukan ada beberapa saran dalam penelitian ini model pembelajaran Means-Ends Analysis (MEA) dengan strategi Lightening The Learning Climate dapat diterapkan agar peserta 
didik lebih aktif dan antusias dalam proses pembelajaran sehingga kemampuan pemecahan masalah matematis peserta didik menjadi lebih baik, dan diharapkan dapat lebih kreatif dalam menggunakan model pembelajaran Means-Ends Analysis (MEA) dengan strategi Lightening The Learning Climate seperti memberikan reward kepada peserta didik yang aktif sehingga dapat membuat peserta didik yang lain semangat dan harus bisa mengorganisir peserta didik dikarenakan peserta didik dalam satu kelas termasuk banyak jika harus diperhatikan satu persatu.

\section{DAFTAR PUSTAKA}

Amorie, J. (2015). Peningkatan Hasil Belajar Matematika Siswa Melalui Strategi Pembelajaran Lightening The Learning Climate. Jurnal EDuMath, 1(1), 73.

Asih, N. (2019). Peningkatan Kemampuan Pemecahan Masalah Matematis dan Kemandirian Belajar Siswa Menggunakan Model Pembelajaran Means End Analysis. Jurnal Pendidikan Matematika.

Hardani, Auliya, N. H., Andriani, H., Fardani, R. A., Ustiawaty, J., Sukmana, D. J., \& Istiqomah, R. R. (2020). Metode Penelitian Kualitatif \& Kuantitatif. CV. Pustaka Ilmu Group.

Hartini, T. I., \& Lianti, M. (2015). Pengaruh Penerapan Model Pembelajaran Means-Ends Analysis (MEA) Terhadap Hasil Belajar Fisika. Jurnal Fisika Dan Pendidikan Fisika, 1(1), 20.

Harto, T. K., Agung, A. A., \& Wibawa, C. (2014). Pengaruh model pembelajaran means-ends analysis (MEA) dengan setting belajar kelompok berbantuan LKS terhadap hasil belajar matematika siswa kelas IV SD Desa Bebetin. E-Journal MIMBAR PGSD Universitas Pendidikan Ganesha, 2(1), 1.

Juanda, M., Johar, R., \& Ikhsan, M. (2014). Peningkatan Kemampuan Pemecahan Masalah dan Komunikasi Matematis Siswa SMP Melalui Model Pembelajaran Means-Ends Analysis (MEA). Jurnal Kreano, 5(2), 109.

Mulasari, M. rika, Wulandari, I. G. A. A., \& Putra, M. (2020). Model Pembelajaran Means Ends Analysis Terhadap Hasil BelajarMatematika Siswa SD. Jurna Padegogik Dan Pendidikan, 3(3), 1.

Natsir, N., Kadir, K., \& Samparadja, H. (2019). Peningkatan Kemampuan Pemecahan Masalah Matematis Siswa SMP Melalui Pendekatan Saintifik Problem posing. Jurnal Pendidikan Matematika. https://doi.org/10.36709/jpm.v9i1. 5766

Nengsih, L. wahyu, Susiswo, \& Cholis sa'dijah. (2019). Kemampuan Pemecahan Masalah Matematika Siswa Sekolah Dasar d engan Gaya Kognitif Field Dependent. Jurnal Pendidikan, 4(2), 143-148.

Nurhadi, M. (2017). Pengaruh MeansEnds Analysis Dalam Meningkatkan Kemampuan Penalaran Matematis Siswa Sekolah Menengah Pertama, Jurnal JPPM , 10(1) , 90

Rachmawati, A. D., Baiduri, \& Effendi, M. M. (2020). Efektivitas Media Pembelajran Interaktif Berbantuan Web Dalam Mengembangkan Kemampuan Berpikir Kreatif. AKSIOMA: Jurnal Program Studi Pendidikan Matematika, 9(3), 541. 
DOI: https://doi.org/10.24127/ajpm.v10i1.3245

Sahrudin, A. (2016). Implementasi Model Pembelajran Means-Ends Analysis Untuk Meningkatkan Kemampuan Pemecahan Masalah Matematika Mahasiswa. Jurnal Pendidikan Unsika, 4(1).

Sari, Y. P., \& Masri, M. (2020). Kemampuan Pemecahan Masalah Matematis Model Pembelajaran Inquiri Terbimbing Dan Means Ends Analysis. Jurnal Math$U M B . E D U$.

https://doi.org/10.36085/mathumb.edu.v7i2.780

Sugiyono. (2013). Metode Penelitian Kuantitatif, kualitatif dan R \& D. Bandung: Alfabeta.

Sumartini, T. S. (2016). Peningkatan Kemampuan Pemecahan Masalah Matematis Siswa melalui Pembelajaran Berbasis Masalah. Jurnal Mosharafa, 5(2), 151.

Untung. (2017). Penerapan Strategi

Pembelajan Lightening The Learning Climate Untuk Meningkatkan Motivasi Belajar Pendidikan Kewarganegaraan (PKN) Siswa Kelas V SDN 06 Lubuk Dalam Kabupaten Siak. Jurnal PAJAR (Pendidikan Dan Pengajaran) Program Studi Pendidikan Guru Sekolah Dasar FKIP Universitas Riau, 1(2), 195. 